\title{
Cerebral Infarction Caused by Thrombolytic Therapy for Acute Myocardial Infarction a Case Report and Literature Review
}

Wei-Chao Liu MM*, Hua Chen MD, Wei Geng MD, Fang Li MD

Department of Cardiovascular, Baoding No.1 Central Hospital, Baoding, 071000, Hebei Province, China

*Corresponding Author: Weichao Liu, MM, Department of Cardiovascular, Baoding No.1 Central Hospital, Baoding, 071000, Hebei

Province, China.

Received date: November 06, 2020; Accepted date: November 19, 2020; Published date: Deceember 01,2020

Citation: Wei-C Liu, H Chen, W Geng, F Li. (2020) Cerebral Infarction Caused by Thrombolytic Therapy for Acute Myocardial Infarction a Case Report and Literature Review. International Journal of Clinical Case Reports and Reviews. 4(4); DOI: 10.31579/2690-4861/091

Copyright: ( $) 2020$ Wei-Chao Liu, This is an open-access article distributed under the terms of the Creative Commons Attribution License, which permits unrestricted use, distribution, and reproduction in any medium, provided the original author and source are credited.

\begin{abstract}
Background: Thrombolytic therapy is one of the effective treatments for ST-segment elevation myocardial infarction. The most common complication of thrombolytic therapy is hemorrhage. Thromboembolism caused by thrombolytic therapy is exceedingly rare in clinical practice. However, we report a case of cerebral infarction caused by thrombolytic therapy for acute myocardial infarction.
\end{abstract}

Case Report: A 70-year-old man complained of burning sensation under the xiphoid process for 7 years and sudden chest pain for 3 hours. He was diagnosed with acute anterior ST-segment elevation myocardial infarction. Thrombolytic therapy was carried out immediately, but the patient developed cerebral infarction 3 hours after thrombolysis.

Conclusion: The common complication of thrombolytic therapy is cerebral hemorrhage or gastrointestinal hemorrhage, but the possibility of cerebral infarction should also be taken into account when patients have neurological symptoms.

Key Words: acute myocardial infarciton; thrombolytic therapy; cerebral infarction

\section{Abbreviations:}

$\mathbf{A M I}=$ acute myocardial infarction,

PCI = percutaneous coronary intervention,

TT = thrombolytic therapy

\section{Introduction}

Acute occlusion of the coronary artery leads to ST-segment elevation myocardial infarction(STEMI) which is a critical condition leading to sudden death. Percutaneous coronary intervention (PCI) and thrombolytic therapy (TT) are two kinds of primary reperfusion therapies [1-4]. Thrombolysis is more readily available although PCI is more efficient than thrombolysis in reperfusion rate. However, primary PCI has many limitations in clinical practice as compared to TT. The mortality rate of acute myocardial infarction (AMI) can be reduced significantly by early TT. However, there are also many side effects of TT, such as reperfusion arrhythmia, skin rash and hemorrhage, especially cerebral hemorrhage and massive hemorrhage of digestive tract, which may lead to death [5, 6]. However, thromboembolism caused by TT is exceedingly rare in clinical practice. We report a case of cerebral infarction caused by TT for AMI. This article suggests that in addition to cerebral hemorrhage, cerebral infarction is also one of the complications of TT. The patient involved in this study- gave written informed consent authorizing the use and disclosure of his protected health information.

The clinical material was available in the electronic medical database of Baoding No.1 Central Hospital, and the patient provided consent for publication of the case.

\section{Case Report}

A 70-year-old male patient was admitted to our hospital with the chief complaint of burning sensation under the xiphoid process for seven years and sudden chest pain for three hours. The patient had a burning sensation under the xiphoid process seven years ago with no obvious trigger. Because the symptoms persisted and could not be alleviated, he consulted the department of cardiology of our hospital. He was diagnosed with AMI and treated with TT seven years ago. He was discharged after improvement. After discharge, the patient did not insist on taking medicine. This time, three hours before admission the patient had sudden chest pain in the anterior cardiac region, accompanied by sweating and shortness of breath. The patient's symptoms could not be alleviated after taking nitroglycerin. He was admitted to the emergency department of our hospital. The patient had a history of hypertension for three years. He did not take antihypertensive drugs regularly and monitor blood pressure. The patient had no relevant personal or family history.

On physical examination, the patient's temperature was $36.8^{\circ} \mathrm{C}$, pulse rate was 57 beats/min, respiratory rate was 18 times/min, and blood pressure was $138 / 84 \mathrm{mmHg}$. No significant abnormalities were found in heart and lung examinations. The Electrocardiogram (ECG) showed sinus rhythm and elevation of ST segment of V1-V6 leads (Figure.1). Creatine kinase isoenzyme (CK-MB) was more than $80 \mathrm{ng} / \mathrm{mL}$ (reference rage, 0$4.3 \mathrm{ng} / \mathrm{mL}$ ), myoglobin (MYO) was more than $500 \mathrm{ng} / \mathrm{mL}$ (reference rage, $0-107 \mathrm{ng} / \mathrm{mL}$ ), and troponin I (cTNI) was more than $30 \mathrm{ng} / \mathrm{mL}$ (reference rage, $0.4-0.99 \mathrm{ng} / \mathrm{mL}$ ). The patient was diagnosed with acute anterior STsegment elevation myocardial infarction. 


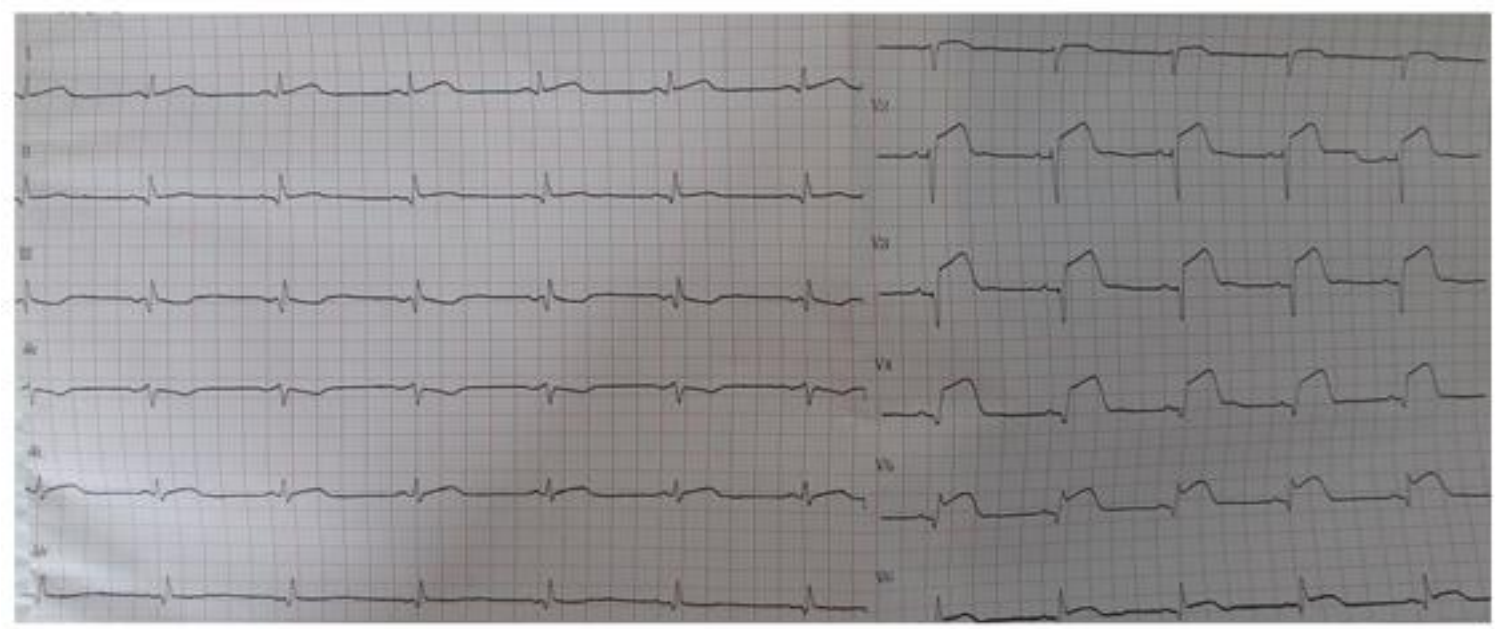

Figure.1 Electrocardiogram showed sinus rhythm and elevation of ST segment of V1-V6 leads

After explanation of the patient's condition to his family members, they chose TT instead of PCI. First, 3000IU of heparin was given intravenously. Then in the fourth hour of chest pain symptoms, $18 \mathrm{mg}$ of reteplase (rPA) was given intravenously. The patient's symptoms could not relieved after 30 minutes. So another $18 \mathrm{mg}$ of reteplase (rPA) was given 30 minutes later. The patient's chest pain relieved 2 hours after thrombolysis, and the ST segment dropped more than $50 \%$ on ECG (Figure.2). The success of TT was considered accordingly.

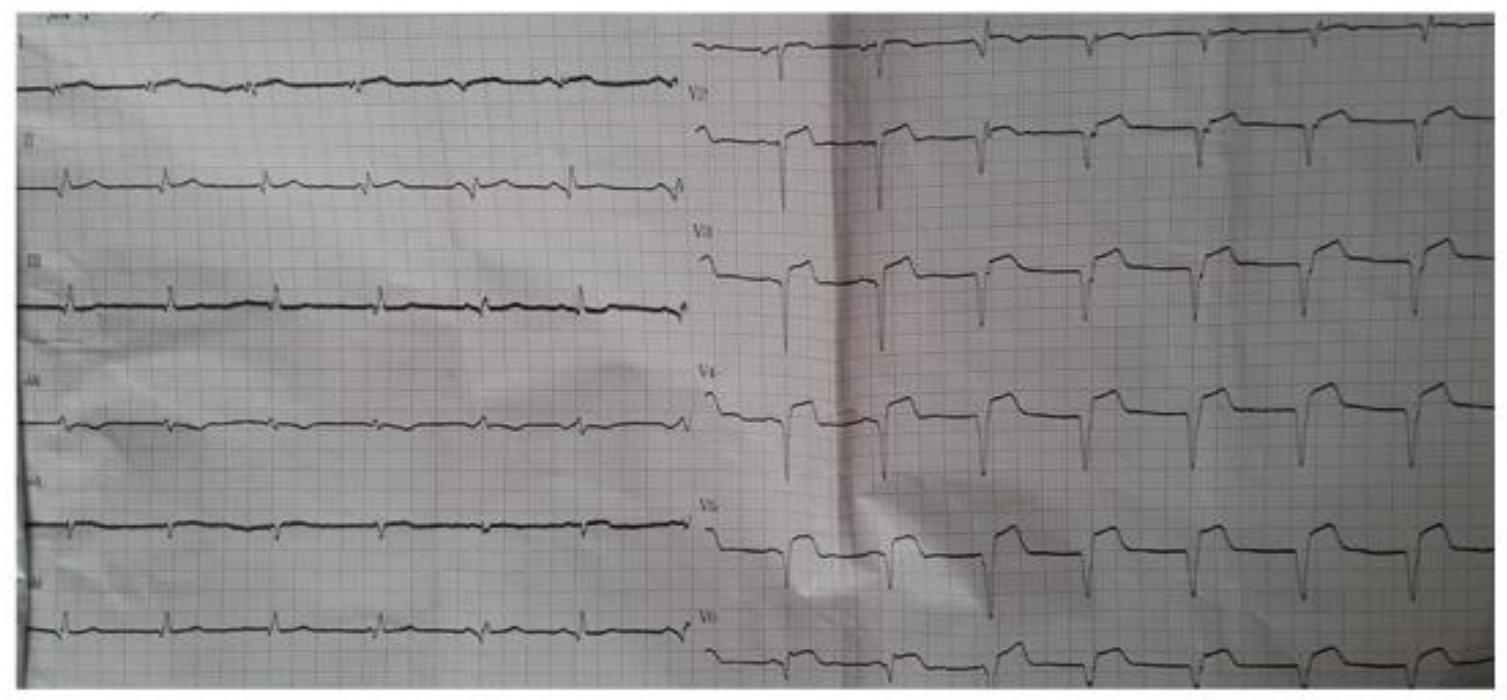

Figure.2 Two hours after thrombolysis, the ST segment dropped more than $50 \%$ on ECG.

However, sudden unconsciousness occurred at the third hour of TT. After awakening, the patient developed speech confusion and limb numbness. Immediate cerebral tomography (CT) was performed and showed lacunar cerebral infarction in bilateral basal ganglia and left corona radiata region (Figure.3).Guided by a neurologist, the patient was treated with Aspirin (100mg,qd), clopidogrel $(75 \mathrm{mg}, \mathrm{qd})$ and atorvastatin $(20 \mathrm{mg}, \mathrm{qn})$. Three days later, the symptoms of chest pain, speech confusion and limb numbness improved markedly and the patient was discharged from hospital. During one year follow-up, no burning sensation under the xiphoid process and chest pain occurred and the patient's speech confusion and limb numbness improved gradually. 


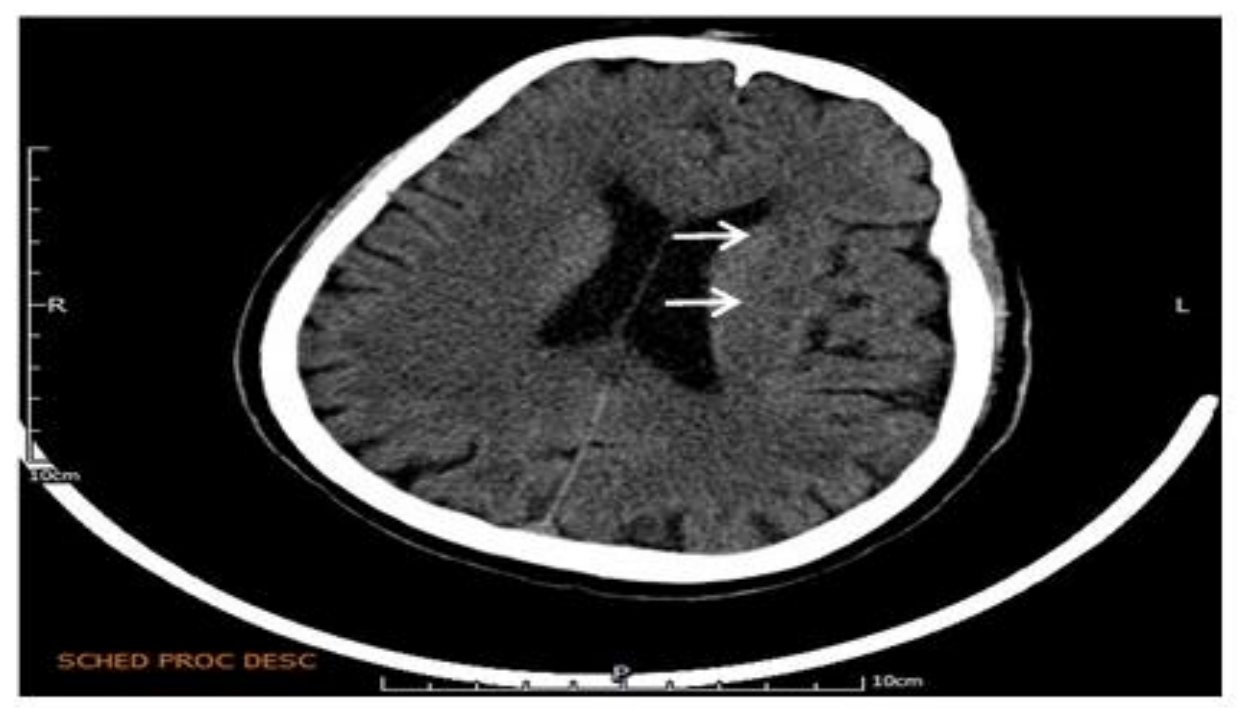

Figure. 3 Immediate cerebral tomography showed that lacunar cerebral infarction was in the bilateral basal ganglia region and the left corona radiata region(white arrows)

\section{Discussion}

The pathogenesis of AMI is complete or subtotal occlusion of the coronary artery caused by intracoronary thrombosis. The study of Boersma showed that about $85 \%$ of patients with STEMI had intracoronary thrombosis [7]. The most effective treatment for AMI is reperfusion therapy, including PCI and TT. Although the rapid development of PCI technology in recent years has reduced the application of thrombolysis in the treatment of AMI, TT is fast, simple, economical and easy to operate which is still an important method of reperfusion therapy $[8,9]$. Especially for grass-roots hospitals which do not have PCI conditions, it is still the preferred treatment plan. Thrombolysis reduces mortality from AMI by approximately $25 \%$. The clinical efficacy is strongly time-dependent, and treatment within the first hour of AMI improves survival rate by nearly $50 \%$ by preventing transmural infarction in a significant proportion of the patients. The disadvantage of thrombolysis is its limited efficacy in terms of rapid, complete and sustained patency of the infarct vessel which yield the optimal results to only $50 \%$ of the patients [10].

Although TT can be implemented quickly and conveniently, it also has some limitations and complications compared with other therapies. The most serious complication of TT is hemorrhage, especially cerebral hemorrhage or gastrointestinal hemorrhage, which may endanger life. The incidence of intracerebral hemorrhage was $0.9 \%$ in patients treated with tissue plasminogen activator (TPA) thrombolysis [11]. The study of Xinyun Liu showed that the reperfusion rate was $89.3 \%$ and the incidence of intracerebral hemorrhage was $0.2 \%$ in patients of STEMI treated with reteplase (rPA) [12]. The complication of TT in this patient is cerebral infarction rather than cerebral hemorrhage, which is an exceedingly rare clinical case. There are only two other case reports in the literature describing embolic cerebral infarction following TT for STEMI. In one case, serial echocardiograms revealed preexisting cardiac thrombi before thrombolysis. It is speculated that the TT induced lysis of fragmentation of thrombus, and the subsequent dislodging of preexisting cardiac thrombi caused the cerebral infarction [13]. In another case, the patient had atrial fibrillation which increased the risk of cerebral thrombosis [14]. Crenshaw's research suggested that TT increased the risk of thrombotic strokes in STEMI patients with atrial fibrillation [15].
However, in this case the patient had neither intracardiac thrombosis nor atrial fibrillation. The causes of cerebral infarction in the patient are not clear, which may be related to the following factors: First, AMI is characterized by high blood viscosity. Thrombolysis ruptures unstable plaques of the cerebrovascular, which leads to thrombosis. Second, TT causes the exfoliation of unstable carotid plaque which leads to cerebral embolism.Third, hemodynamic instability and the slow speed of blood flow caused by AMI can lead to cerebral hypoperfusion which induced thrombosis.

\section{Conclusion}

When hemiplegia and disturbance of consciousness occur after thrombolytic therapy in patients with AMI, not only hemorrhagic stroke but also ischemic stroke should be considered. After the occurrence, we should make a definite diagnosis as soon as possible and adjust the treatment plan so as to avoid delaying the condition. In addition, before thrombolysis, routine informing of the risk of cerebral infarction should be carried out to avoid unnecessary disputes.

Conflicts of Interest: The authors have no conflicts of interest to disclose

\section{References}

1. Vyshlov EV, Avetisyan VY, Kuzeleva EA et al. (2018) Inhospital and long-term results of delayed percutaneous coronary intervention after successful thrombolytic therapy in elderly patients with acute myocardial infarction. Adv Gerontol.31 (1):121-125.

2. Gultekin N, Bulut G, Kucukates E et al. (2016) Apoptosis kinetics at reperfusion period in patients with acute ST-Segment Elevation Myocardial Infarction undergoing primary percutaneous coronary intervention and treated with thrombolytic therapy.J Pak Med Assoc. Jul;(7):808-814.

3. Weiwei Xu, Liaohang Xu, Jiren Peng et al. (2019) Thrombolytic therapy in a patient with chest pain with de Winter ECG pattern occurred after ST-segment elevation: A case report.Journal of Electrocardiology. Jun 12; 56:4-6.

4. Kocayiqit I, Yaylaci S, Osken A et al. (2019) Comparison of effects of thrombolytic therapy and primary percutaneous 
coronary intervention in elderly patients with acute ST-segment elevation myocardial infarction on in-hospital,six-month,and oneyear mortality.Arch Med Sci Atheroscler Dis.2019 May 27(4):8288.

5. Kluft C, Sidelmann JJ, Gram JB. (2017) Assessing Safety of Thrombolytic Therapy.Semin Thromb Hemost. Apr; 43(3):300310.

6. Zhao G, Huang T, Zheng M. (2018) Comparative Analysis on Low and Standard Dose Regimes of Alteplase Thrombolytic Therapy for Acute Ischemic Stroke:Efficacy and Safety. Eur Neurol.79 (1-2):68-73.

7. Boersma E, Mercado N, Poldermans D et al. (2003) Acute myocardial infarction. Lancet. 361: 847-858.

8. Eagle KA, Nallamothu BK, Mehta RH et al. (2008) Trends in acute reperfusion therapy for ST-segment elevation myocardial infarction from 1999 to 2006: we are getting better but we have got a long way to go [J].Eur Heart J.29:609-617.

9. Himmatrao S, Bawaskar, Pramodini H et al. (2019) Preintensive care: Thrombolytic (streptokinase or tenecteplase) in ST elevated acute myocardial infarction at peripheral hospital.J Family Med Prim Care. Jan;8(1):62-71.

10. Voqt A, Neuhaus KL. (1999) Therapy of acute myocardial infarctprimary PTCA or thrombolysis? Herz.Aug; 24(5):363-368.

11. Marder VJ, Stewart D. (2002) Towards safer thrombolytic therapy. Semin Hematol. 39(3): 206-216.

12. Liu XY, Zhang Y, Li MW et al. (2016) Efficacy of thrombolytic therapy using reteplase in cases with acute ST-segment elevation myocardial infarction: results from a multicenter clinical trial.Zhonghua Xin Xue Guan Bing Za Zhi.Sep24;44(9):766-770.

13. Chang MC, Lee AY, Chang WF, et al. (2002) Embolic cerebral infarction and gastrointestinal hemorrhage following thrombolytic therapy for acute myocardial infarction. Echocardiography. 19(2): 139-141.

14. Bostan M, Kanat A, Sen M, et al. (2010) Cerebral embolism following thrombolytic therapy for acute myocardial infarction: the second reported case.Cardiovasc J Afr. 21:155-157.

15. Crenshaw BS, Ward SR, Granger CB et al. (1997) Atrial fibrillation in the setting of acute myocardial infarction: the GUSTO-I experience. Global Utilization of Streptokinase and TPA for Occluded Coronary Arteries. J Am Coll Cardiol. 30(2): 406-413.

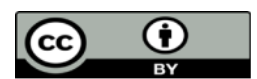

This work is licensed under Creative Commons Attribution 4.0 License

To Submit Your Article Click Here: Submit Article

DOI: $10.31579 / 2690-4861 / 091$

\author{
Ready to submit your research? Choose Auctores and benefit from: \\ * fast, convenient online submission \\ * rigorous peer review by experienced research in your field \\ * rapid publication on acceptance \\ * authors retain copyrights \\ * unique DOI for all articles \\ * immediate, unrestricted online access
}

At Auctores, research is always in progress.

Learn more www.auctoresonline.org/journals/international-journalof-clinical-case-reports-and-reviews- 